\title{
Carbon Emission Policy Research Based on the ECM model of Energy Consumption and GDP of Shandong Province
}

\author{
Li Yanhong \\ Department of Economic Management \\ North China Electric Power University \\ Baoding, Hebei \\ redlyh@126.com
}

\begin{abstract}
China has paid more attention to the carbon emission of energy consumption, from the outline of the "eleventh five-year plan". As the first major energy consumption province, Shandong province should strictly control carbon emission. This article uses econometrics methods to study the intrinsic relationship between economic growth and fossil energy carbon emissions, including long-term and short-term. Through the time series of unit root test, co-integration test and granger causality test, error correction model is established, and the results show that the economic growth and carbon emissions in Shandong province has a long-term and stable relations, and short-term deviation can adjust to long-term equilibrium gradually. Granger causality tests show that they have granger relationship. Finally, according to the research conclusion, the corresponding policy Suggestions are put forward.
\end{abstract}

Keywords-carbon emission; economic growth; co-integration test; ECM model

\section{INTRODUCTION}

With the excessive consumption of fossil fuels having a significant impact on global climate change, China has taken a series of corresponding measures. During "Twelfth five-year" period, the national energy consumption per unit GDP reduced by $18.4 \%$, and the total discharge of major pollutants such as sulfur dioxide, ammonia nitrogen have reduced about $15 \%$ respectively. ${ }^{[1]}$ In the "Thirteenth five-year" plan, energy conservation and emissions reduction work has made the further requirement and target. By 2020, the national energy consumption per unit GDP is going to reduce by $15 \%$ lower than in 2015, and the total energy consumption will be controlled within 5 billion tons of standard coal. Shandong, as a major energy consuming province, accounts for about $8 \%$ of the total energy consumption, should formulate policies to conserve energy and reduce emissions. Shandong coal consumption proportion is as high as $80 \%$, at the same time, the total coal consumption and high proportion is the prominent contradictions of energy structure, so it is also the main direction of future energy structure adjustment in Shandong province. In 2015, the total amount of chemical oxygen demand in Shandong province was 175.76 million tons, and the total amount of ammonia nitrogen emissions was 15.26 million tons, ranking among the highest. ${ }^{[2]}$ Nitrogen and sulfur emissions are also at a high level. The pollutant

Fund project: Central University fund "Energy structure optimization model of Beijing-Tianjin-Hebei region.” (2015ZD33) emission in Shandong province is significantly higher than that of Jiangsu, Zhejiang, Guangdong and other coastal economic developed provinces. Questions like whether Shandong can fulfill the emissions reduction commitments while maintaining rapid development highlight the importance of research on policy of carbon emission.

The current research on carbon emission policy is focused on influencing factors. Wang C. used the e-g two-step method to examine the relationship between energy consumption and income between 1974 and 1990 in the United States, and they think there was no long-term co-integration relationship. ${ }^{[3]}$ Zhang B. studied the data on energy consumption, GDP and labor demand between 1955 and 1993 in Taiwan, and there was no agreement between them. ${ }^{[4]}$ Yang examines the relationship between GDP and energy consumption as a single source of energy, and he finds a two-way link between GDP and energy consumption. ${ }^{[5]}$ Some scholars believe that the sequence of GDP and carbon emission in our country is integrated of order one, and some scholars have verified that these two sequences are integrated of order two. But it is widely believed that there is a long-term stable co-integration relationship. In conclusion, it can be seen that GDP and carbon emissions sequences of co-integration test and granger causality test is a widely used, but on the basis of the data sample, region and so on, the inspection results and the research conclusions are also different. It can be seen that the conclusion must be specific to the study period and area. This paper studies the relationship between economic growth and carbon emission in Shandong province, including long-term and short-term relationship, and the causal relationship between them. On this basis, it puts forward energy policy suggestion in Shandong province.

\section{ECONOMETRIC ANALYSIS OF THE RELATIONSHIP BETWEEN ENERGY CONSUMPTION AND ECONOMIC GROWTH OF SHANDONG PROVINCE}

\section{A. Data Processing and Analysis}

In order to study the inherent relationship between economic growth and carbon emission in Shandong province, the data from 1995 to 2015 are selected for empirical study due to the limitations of data availability. Economic growth is measured by real GDP, based on 2010.Carbon emission 
selects the annual energy consumption of coal, oil and natural gas in Shandong province, and calculates the carbon emission by the conversion coefficient, which is based on the same idea that Yang Guiyuan ${ }^{[6]}$ and others estimate China's carbon dioxide emissions, Formula is as follows TPF $=\sum_{i=1}^{3} E_{i} F_{i}$. Among them, TPF is the total carbon emission caused by fossil energy consumption, and $E_{i}$ represents the consumption of all kinds of energy. And $F_{i}$ represents the carbon emission coefficient of all kinds of fossil energy in China, ( $i=1,2,3$ represents three types of energy: coal, oil, natural gas). While the value of $F_{i}$ is the average value of the coefficients obtained by multiple institutions.

TABLE I. CARBON EMISSION COEFFICIENTS OF THREE TYPES OF ENERGY

\begin{tabular}{c|c|c|c}
\hline Data sources & Coal & Oil & Gas \\
\hline IEEJ & 0.756 & 0.586 & 0.449 \\
DOE/EIA & 0.702 & 0.478 & 0.389 \\
\hline
\end{tabular}

As seen from Fig. 1, before 2000, the GDP growth of Shandong province was relatively slow, but after 2000, the GDP growth rate was significantly faster. Before 2000, real GDP growth was averaged about $10 \%$. In the 21 st century, with the industrialization process advancing, the third industry developing gradually, and the market system standardized and perfected, the real GDP growth in Shandong province is about 14 percent.

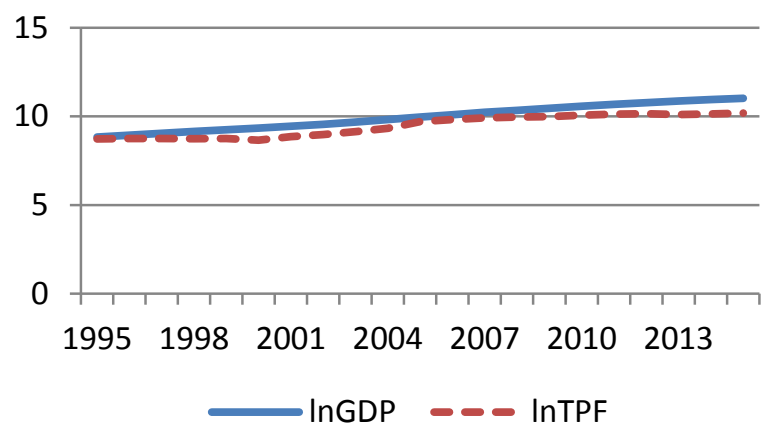

Fig. 1.Real GDP and carbon emission trends

It also shows the change of carbon emission in Shandong province from 1995 to 2014. Based on the actual situation of the serious dependence of economic growth on energy consumption, the change of carbon emissions is consistent with the actual GDP transformation. The real GDP and carbon sequence are obvious non-stationary sequence, which have similar trends. In order to overcome the larger data volatility, the two sequences are taken logarithm.

\section{B. ADF Test and Co-integration Test}

ADF tests of $\operatorname{lnGDP}$ and $\operatorname{lnTPF}$ sequences are performed using E-views. (C, T, K) represents the constant term, trend term and lagging order of the test equation, and $\mathrm{N}$ means no constant term or trend term. According to the ADF test method, if the original sequence is not stable, the differential sequence is checked until it is stable.

The co-integration model of two variables is established with the ordinary least square method, and the results are as follows:

$$
\ln (G D P)_{t}=-0.679415+1.122907 \ln (T P F)_{t}
$$

$$
(-1.033316)(16.20333)
$$

According to the test results, the residual is stable, which means that lnGDP and lnTPF sequences have long-term cointegration relationship. And economic growth and carbon emissions of Shandong province have a long-term stable relationship.

TABLE II. ADF TEST RESULTS

\begin{tabular}{c|c|c|c|c}
\hline Variables & Test form & ADF value & T value & result \\
\hline $\mathrm{D}(\operatorname{lnGDP}, 2)$ & $(\mathrm{N}, \mathrm{N}, 0)$ & -2.644230 & -1.961409 & stable \\
\hline $\mathrm{D}(\operatorname{lnTPF}, 2)$ & $(\mathrm{C}, \mathrm{T}, 0)$ & -6.212909 & -4.571559 & stable \\
\hline
\end{tabular}

After the ADF test, the $\operatorname{lnGDP}$ and $\ln T P F$ sequences are all two order sequences, and the test results are shown in TABLE II.

\section{ECM Model}

Considering the relationship between total carbon emissions and GDP in the short term has deviation, in order to measure the adjustment of short-term deviation to long-term equilibrium, obtained by the regression residual sequence as unbalanced error directly used for error correction model, the ECM model of second order delay is established, and then estimated by OLS method.

$$
\begin{gathered}
Y_{t}=\beta_{0}+\beta_{1} X_{t}+\beta_{2} X_{t-1}+\beta_{3} Y_{t-1}+\beta_{4} X_{t-2}+ \\
\beta_{5} Y_{t-2} \varepsilon_{t} \mathrm{t}=1,2,3 \ldots \ldots \\
\Delta Y_{t}=-\beta_{5} \Delta Y_{t-1}+\beta_{1} \Delta X_{t}-\beta_{4} \Delta X_{t-1}-\lambda\left(Y_{t-1}-\alpha_{0}-\right. \\
\left.\widehat{\alpha_{1}} X_{t}\right)+\varepsilon_{t} \mathrm{t}=1,2,3 \ldots \ldots \\
\lambda=1-\beta_{3}-\beta_{5}, \alpha_{0}=\frac{\beta_{0}}{\lambda}, \alpha_{1}=\frac{\beta_{1}+\beta_{2}+\beta_{4}}{\lambda}
\end{gathered}
$$

Between 1995 and 2015, there is a long-term equilibrium between the actual GDP sequence of Shandong province and the carbon emission. When the province's carbon emissions rises by a percentage point, total GDP in Shandong province rises by nearly 1.1 percent. Because of the long-term stable cointegration relationship between these two sequences, the economic system has a tendency to stabilize in the long term, no matter how it changes in the short term.

In the short term, the economic system will deviate from the long-term equilibrium, but its own forces will adjust to the equilibrium. The short-term deviation between the carbon emission in Shandong province and the real GDP will be adjusted gradually to the long-term equilibrium. By 
establishing the second-order hysteresis error correction model, the adjustment strength is around 2.85\%.

TABLE III. RESULTS OF ECM MODEL

\begin{tabular}{c|c|c|c|c}
\hline Parameter & $-\beta_{5}$ & $\beta_{1}$ & $-\beta_{4}$ & $-\lambda$ \\
\hline Estimate & 0.948982 & 0.000939 & 0.048852 & 0.028543 \\
\hline T- stat. & $(38.8908)$ & $-0.039)$ & $(2.0434)$ & $(2.124503)$ \\
\hline
\end{tabular}

In order to maintain economic growth in Shandong province and the long-term stability of the relationship between carbon emissions and GDP, carbon emissions and short-term deviation will gradually adjust to the long-term equilibrium, with the speed of 0.0285 .

\section{GRANGER CAUSALITY TEST}

We use granger causality test to examine the causal relationship between carbon emission and economic growth in Shandong province.

As seen from TABLE IV, economic growth and carbon emission are two-way causality. Combined with the economic development of Shandong province and the actual situation of energy consumption, this conclusion accords with the actual economic significance: increased energy consumption is one of many drivers to economic growth, especially in such a large energy consumption in Shandong province, and more and more energy consumption means that more and more carbon emissions, so carbon emissions is the granger cause of economic growth; On the other hand, the economic growth level of Shandong province is in the forefront of the country, but it is still underdeveloped in general. In the economic growth mode which relies heavily on energy consumption, the more economic growth, the more energy consumption. Energy consumption is also inefficient and extensive, which will inevitably lead to an increase in carbon emissions. Combined with the development of economy, the increasing population, infrastructure construction and advance of the construction of the urbanization has led to increased carbon emissions, so that, in turn, economic growth is granger cause of carbon emissions.

TABLE IV. RESULT OF GRANGER CAUSALITY TEST

\begin{tabular}{c|c|c|c}
\hline Lags & Null hypothesis & P value & conclusion \\
\hline 1 & GDP is not cause & 0.3897 & accept \\
2 & GDP is not the cause & 0.00001 & reject \\
1 & Carbon emission is not the cause & 0.0886 & accept \\
2 & Carbon emission is not the cause & 0.0200 & reject \\
\hline
\end{tabular}

\section{CONCLUSION AND CARBON EMISSION POLICY RECOMMENDATIONS}

\section{A. Conclusion}

This paper studies the relationship between carbon emission and economic growth of Shandong province from 1995 to 2015. The study shows that there is a co-integration relationship between the actual GDP sequence and the carbon emission sequence, which means they have a long-term equilibrium relationship. In the short term, the deviation between carbon emission and real GDP in Shandong province will gradually adjust to long-term equilibrium. By establishing the second-order hysteresis error correction model, the adjustment force is around $2.85 \%$.

\section{B. Carbon Emission Policy Recommendations}

Economic development in Shandong province is relying on energy consumption, but energy efficiency is low. So the optimization industry structure should be adjusted. The aim of the adjustment of industrial structure in Shandong province is to break the restriction and cultivate a number of leading enterprises with strong market competitiveness. At the same time, we will eliminate and annex some of the weak and backward technologies to control energy consumption. In addition, increasing the contribution of tertiary industry to GDP will promote the development of high-tech industries with low energy consumption, which can reduce the dependence of economic growth on energy consumption, and can also form the growth potential of economic development.

We should fully implement the country's stimulus policies on promoting the development of new energy and renewable energy, investment, credit and taxation, and formulate supporting policies for the implementation of tax incentives, special fund support, and temporary subsidized electricity prices, also guide the development of new energy and renewable energy from all sectors of society. However, the power of the government should continue to deepen the energy prices and production process a large amount of energy market reform of price of the product, use price leverage to adjust energy consumption structure. The market mechanism of "carbon trading" ${ }^{[7]}$ is promoted, and the carbon emission of enterprises is limited, so as to set up a good platform for the carbon trading parties.

\section{REFERENCES}

[1] Qiu J. China asks world to step up on climate. [J] Nature 2008:456-150. ( in Chinese)

[2] Wang C. Wang F. Zhang H. Carbon emissions decomposition and environmental mitigation policy recommendation for sustainable development in Shandong province.[J] Sustainability 2014,6:8164-79. (in Chinese)

[3] Jotzo F, Burke PJ, Macintosh A. Decomposing the 2010 global carbon dioxide emissions rebound. [J] Nat Clim Change 2012, 2: 672-675.

[4] Zhang B, Chen GQ. Methane emissions in China 2007, Renew Sustain Energy Rev [M] 2014, 30: 886-901. (in Chinese)

[5] Zheng Y, Industrial structure and oil consumption growth path of China: empirical evidence. Energy [M] 2013, 57: 314-44.

[6] Yang G.Y. Econometric analysis of the relationship between carbon emission and economic growth in Anhui province. [J] Statistics and Decision 2012, 17: 106-109. ( in Chinese) 
